\title{
NOVAS DATAÇÕES ARQUEOLÓGICAS EM MATO GROSSO DO SUL
}

\begin{abstract}
Pesquisas arqueológicas em desenvolvimento no contexto sul-mato-grossense vêm produzindo significativos resultados cronológicos referentes aos diversos horizontes culturais históricos e précoloniais presentes nesse Estado. Esta nota objetiva divulgar as novas datações arqueológicas obtidas a partir dos trabalhos científicos realizados no alto curso do rio Paraná (Projeto Arqueológico Porto Primavera, $M S$ - código 2 nas tabelas a seguir) e em outras paisagens dessa bacia hidrográfica em Mato Grosso do Sul.
\end{abstract}

As datações do material cerâmico, empregando-se o método da termoluminescência, foram realizadas no Laboratório de Vidros e Datação da Faculdade de Tecnologia de São Paulo (FATEC), sob a coordenação da Profa. Dra. Sonia H. Tatumi. As amostras de carvão foram datadas por meio da aplicação do método do carbono 14 (C14), no Laboratoire des Sciences du Climat et de l'Environnement - Laboratóire Mixte CEA-CNRS UMR 1572, em Gif-sur-Yvette/França - (Gif), sob a responsabilidade do Dr. Michel Fontugne.

Gilson Rodolfo Martins* Emília Mariko Kashimoto** Sonia Hatsue Tatumi*** 


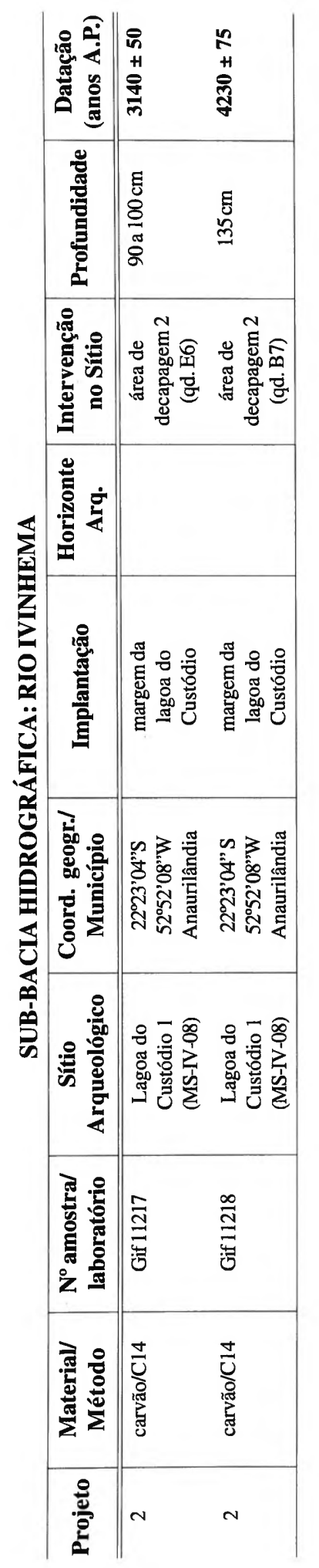

\begin{tabular}{|c|c|c|c|c|c|c|c|}
\hline 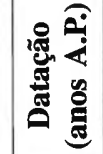 & 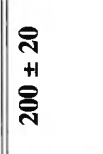 & 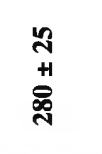 & $\begin{array}{l}8 \\
8 \\
ث 1 \\
0\end{array}$ & 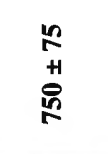 & 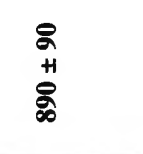 & 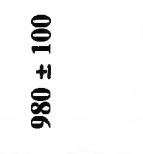 & 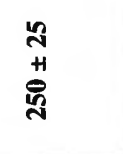 \\
\hline 童 & 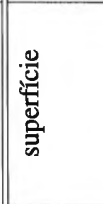 & 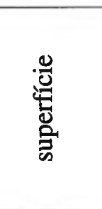 & 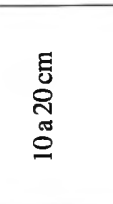 & 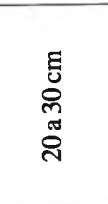 & $\begin{array}{l}\frac{5}{8} \\
\frac{0}{8}\end{array}$ & 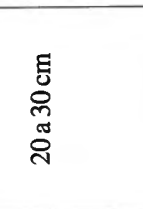 & $\begin{array}{l}\text { 总 } \\
\text { d. } \\
\text { a }\end{array}$ \\
\hline 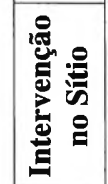 & 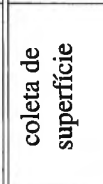 & 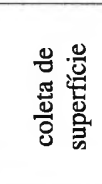 & 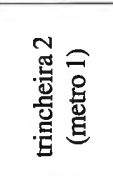 & 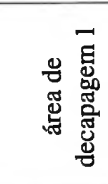 & 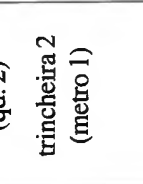 & 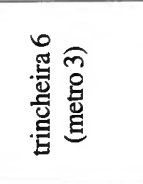 & 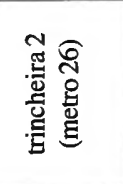 \\
\hline 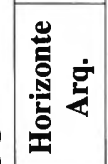 & 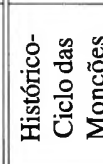 & $\frac{1}{8}$ & & 氪 & 感 & 苞 & 荨 \\
\hline$\overline{\underline{\mathbf{s}}}$ & 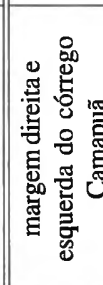 & 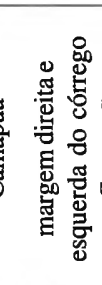 & 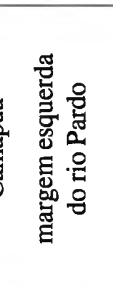 & 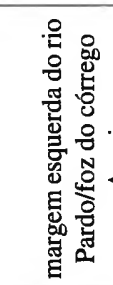 & 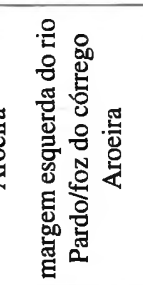 & 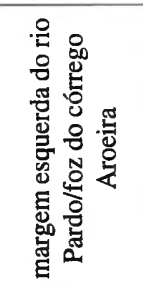 & 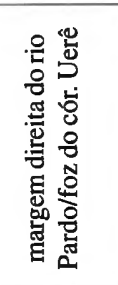 \\
\hline 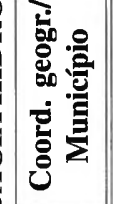 & 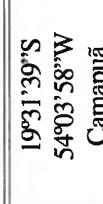 & & 2 & 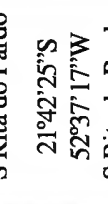 & & & 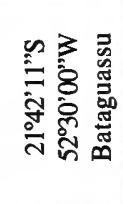 \\
\hline 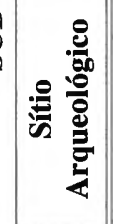 & 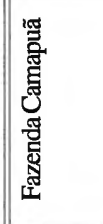 & 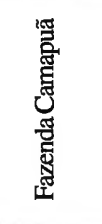 & 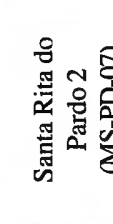 & & 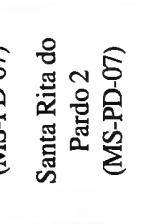 & 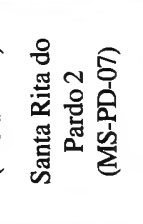 & 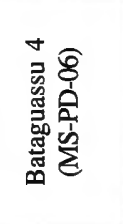 \\
\hline 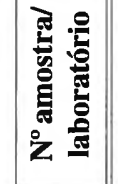 & 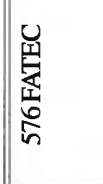 & 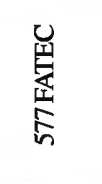 & 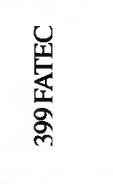 & 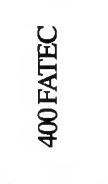 & 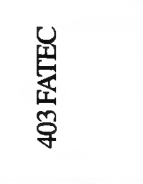 & 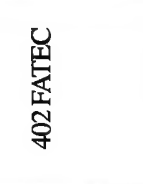 & 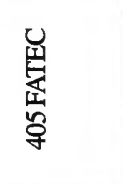 \\
\hline 产 & 局 & 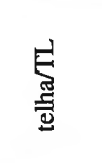 & 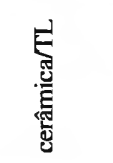 & 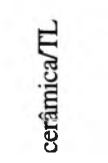 & 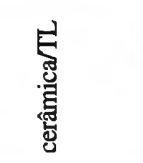 & 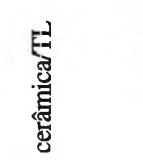 & 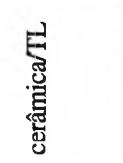 \\
\hline & & o & w & w & 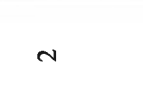 & 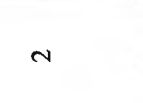 & N \\
\hline
\end{tabular}




\begin{tabular}{|c|c|c|c|c|c|c|c|c|c|c|}
\hline 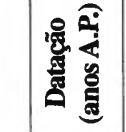 & $\begin{array}{l}8 \\
+ \\
\vdots \\
y \\
y\end{array}$ & $\begin{array}{l}8 \\
\text { H } \\
\text { \& } \\
\text { in }\end{array}$ & $\begin{array}{l}\text { o } \\
+1 \\
\stackrel{F}{\infty}\end{array}$ & $\begin{array}{l}\stackrel{O}{\Xi} \\
\stackrel{+}{\Xi}\end{array}$ & $\begin{array}{l}\text { ? } \\
+1 \\
\text { İ }\end{array}$ & \begin{tabular}{l} 
\& \\
+1 \\
\multirow{3}{*}{} \\
t
\end{tabular} & $\begin{array}{l}\infty \\
e \\
+1 \\
0 \\
0 \\
N\end{array}$ & $\begin{array}{l}m_{n} \\
+ \\
\stackrel{N}{+}\end{array}$ & $\begin{array}{l}\text { : } \\
\text { +1 } \\
\text { §ิ }\end{array}$ & 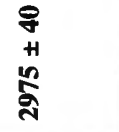 \\
\hline 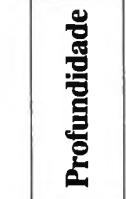 & 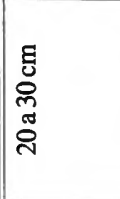 & $\begin{array}{l}\frac{E}{0} \\
\frac{0}{8} \\
8\end{array}$ & $\begin{array}{l}E \\
8 \\
\frac{8}{\pi} \\
8\end{array}$ & 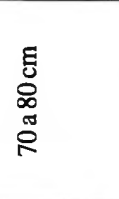 & $\begin{array}{l}\text { E } \\
\stackrel{0}{0} \\
\stackrel{0}{O}\end{array}$ & 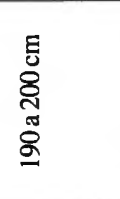 & 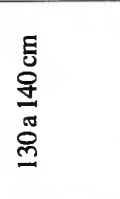 & 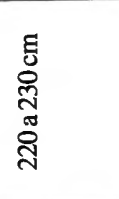 & 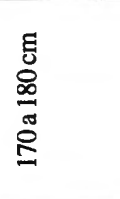 & 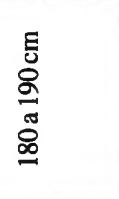 \\
\hline 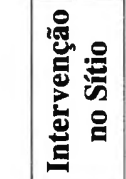 & 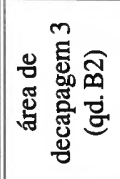 & 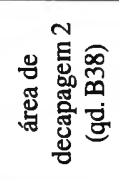 & 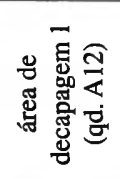 & 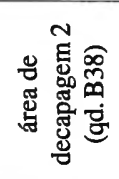 & 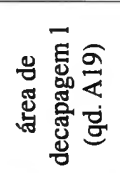 & 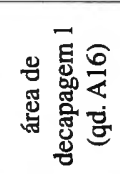 & 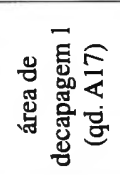 & 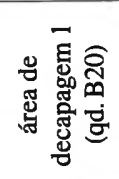 & 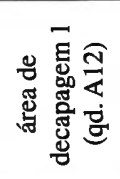 & 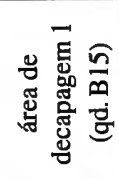 \\
\hline 总 & '] & & & & & & & & & \\
\hline 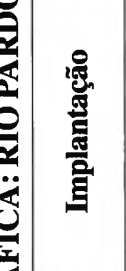 & 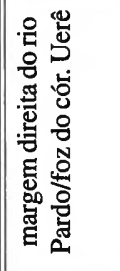 & 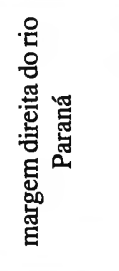 & 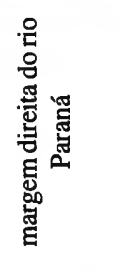 & 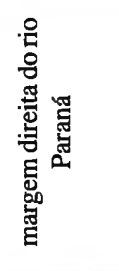 & 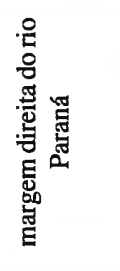 & 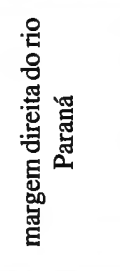 & 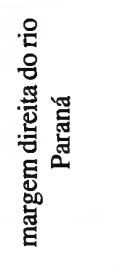 & 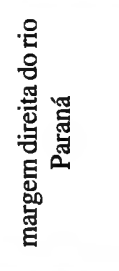 & 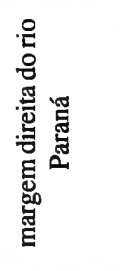 & 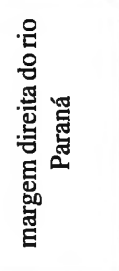 \\
\hline 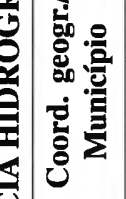 & 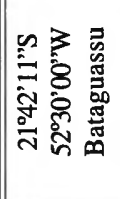 & 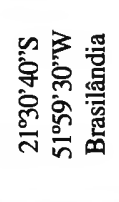 & 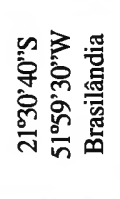 & 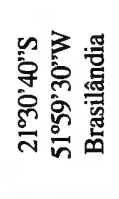 & 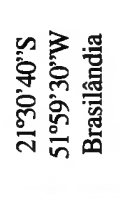 & 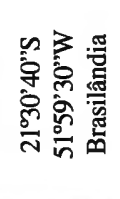 & 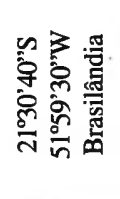 & 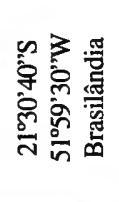 & 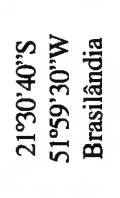 & 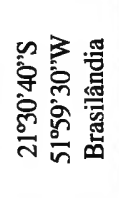 \\
\hline 苟 & 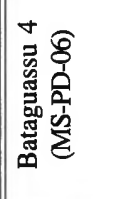 & 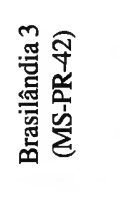 & 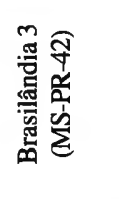 & 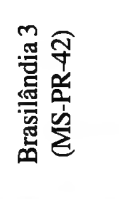 & 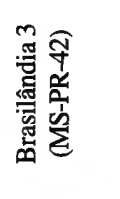 & 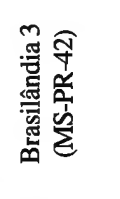 & 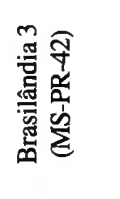 & 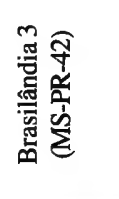 & 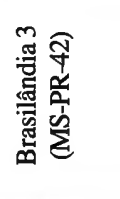 & 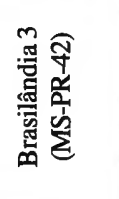 \\
\hline 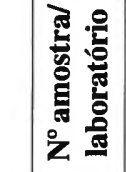 & 焉 & 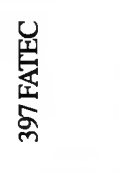 & 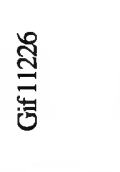 & 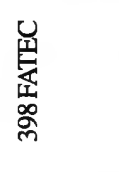 & 矛 & 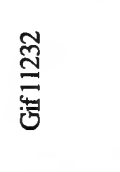 & 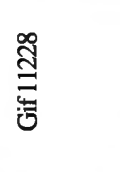 & 节 & 点 & $\frac{\bar{\Xi}}{\bar{\Xi}}$ \\
\hline 焉 & 炭 & 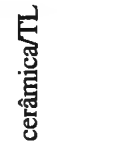 & 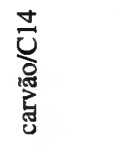 & 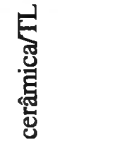 & 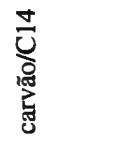 & 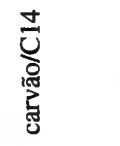 & 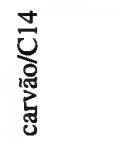 & 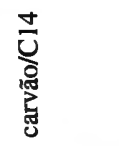 & 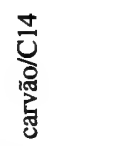 & 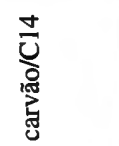 \\
\hline & $N$ & $N$ & $N$ & $N$ & $N$ & $N$ & $N$ & $N$ & $N$ & $N$ \\
\hline
\end{tabular}




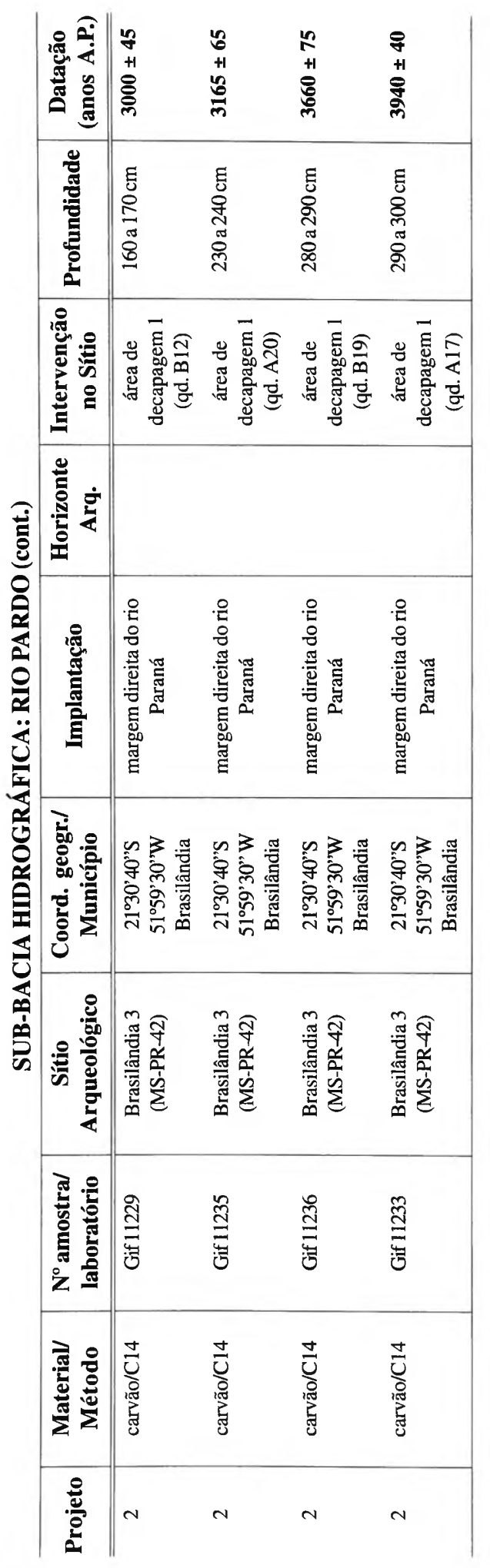

\begin{tabular}{|c|c|c|c|c|c|}
\hline 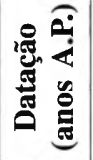 & $\mid \begin{array}{l}n \\
+1 \\
\tilde{m} \\
\stackrel{n}{2}\end{array}$ & $\begin{array}{l}n \\
+1 \\
n \\
n\end{array}$ & $\begin{array}{l}8 \\
+1 \\
10 \\
0 \\
0\end{array}$ & $\begin{array}{l}8 \\
+1 \\
\frac{9}{9}\end{array}$ & $\begin{array}{l}R \\
+1 \\
+1 \\
\infty \\
\stackrel{9}{2}\end{array}$ \\
\hline 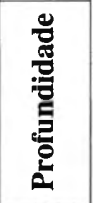 & 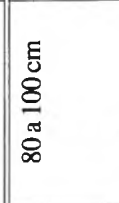 & 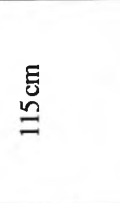 & 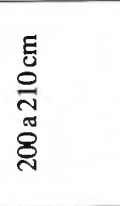 & 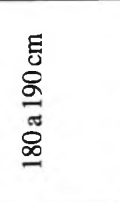 & $\begin{array}{l}\varepsilon \\
\varrho\end{array}$ \\
\hline 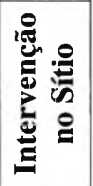 & 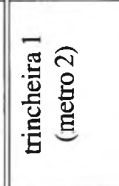 & 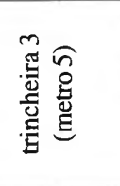 & 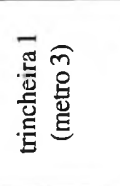 & 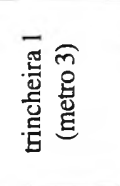 & 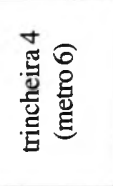 \\
\hline 递 & & & & & \\
\hline 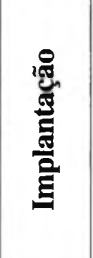 & 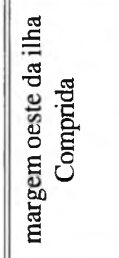 & 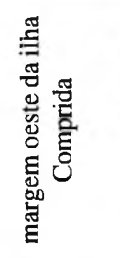 & 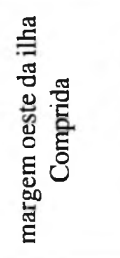 & 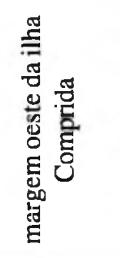 & 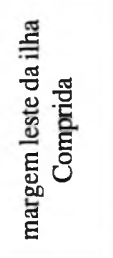 \\
\hline 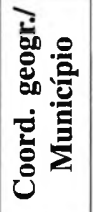 & 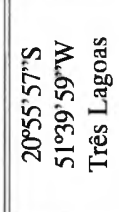 & 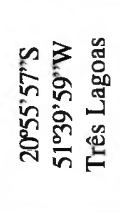 & 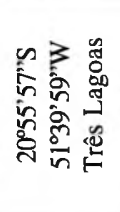 & 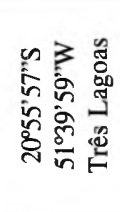 & 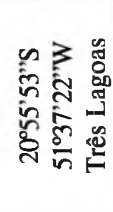 \\
\hline 的 & 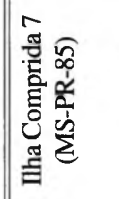 & 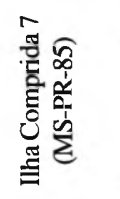 & 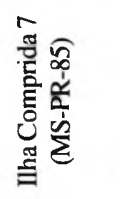 & 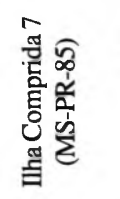 & 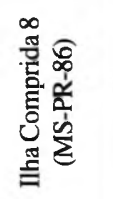 \\
\hline 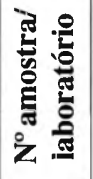 & 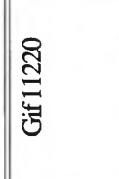 & 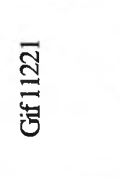 & $\frac{\tilde{\Xi}}{\Xi}$ & $\underset{\Xi}{\mathbb{Z}}$ & 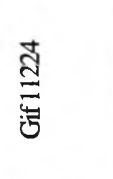 \\
\hline 衰 & 紊 & 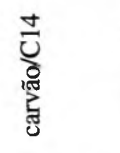 & 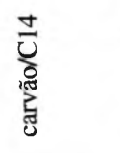 & 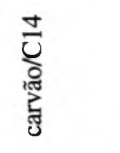 & 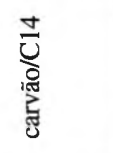 \\
\hline 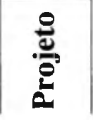 & $\sim$ & $N$ & $N$ & $N$ & N \\
\hline
\end{tabular}

